Article

\title{
Study on the Ground-Based FTS Measurements at Beijing, China and the Colocation Sensitivity of Satellite Data
}

\author{
Sen Yang ${ }^{1,2}$, Xiaoyang Meng ${ }^{3}$, Xingying Zhang ${ }^{2, *}$, Lu Zhang ${ }^{2}$, Wenguang Bai ${ }^{2}$, Zhongdong Yang ${ }^{2}$, \\ Peng Zhang ${ }^{2}{ }^{\infty}$, Zhili Deng ${ }^{1,2}$, Xin Zhang ${ }^{1,2}$ and Xifeng Cao ${ }^{1,4}$ \\ 1 Chinese Academy of Meteorological Sciences, China Meteorological Administration, Beijing 100081, China; \\ threadjum@gmail.com (S.Y.); dengzhili19@mails.ucas.ac.cn (Z.D.); zhangxin202@mails.ucas.ac.cn (X.Z.); \\ 21113020001@m.fudan.edu.cn (X.C.) \\ 2 National Satellite Meteorological Center, China Meteorological Administration, Beijing 100081, China; \\ zhanglu_nsmc@cma.gov.cn (L.Z.); baiwg@cma.gov.cn (W.B.); yangzd@cma.gov.cn (Z.Y.); \\ zhangp@cma.gov.cn (P.Z.) \\ 3 Institute of Electrical Engineering, Chinese Academy of Sciences, Beijing 100190, China; \\ mengxiaoyang@mail.iee.ac.cn \\ 4 Department of Atmospheric and Oceanic Sciences, Fudan University, Shanghai 200438, China \\ * Correspondence: zxy@cma.gov.cn
}

check for updates

Citation: Yang, S.; Meng, X.; Zhang, X.; Zhang, L.; Bai, W.; Yang, Z.; Zhang, P.; Deng, Z.; Zhang, X.; Cao, X. Study on the Ground-Based FTS

Measurements at Beijing, China and the Colocation Sensitivity of Satellite Data. Atmosphere 2021, 12, 1586. https://doi.org/10.3390/ atmos12121586

Academic Editor: Amal Chandran

Received: 7 October 2021

Accepted: 25 November 2021

Published: 29 November 2021

Publisher's Note: MDPI stays neutral with regard to jurisdictional claims in published maps and institutional affiliations.

Copyright: (c) 2021 by the authors. Licensee MDPI, Basel, Switzerland. This article is an open access article distributed under the terms and conditions of the Creative Commons Attribution (CC BY) license (https:/ / creativecommons.org/licenses/by/ $4.0 /)$.

\begin{abstract}
The Fourier Transform Spectrometer (FTS) at the Beijing Satellite Meteorological Ground Station observed $\mathrm{XCO}_{2}$ (the dry carbon dioxide column) from 2 March 2016 to 4 December 2018. The validation results of ground-based $\mathrm{XCO}_{2}$, as well as GOSAT, OCO-2, and TanSat $\mathrm{XCO}_{2}$, show that the best temporal matching setting for ground-based $\mathrm{XCO}_{2}$ and satellite $\mathrm{XCO}_{2}$ is $\pm 1 \mathrm{~h}$, and the best spatial matching setting for GOSAT is $0.5^{\circ} \times 0.5^{\circ}$. Consistent with OCO-2, the best spatial matching setting of TanSat is $5^{\circ} \times 5^{\circ}$ or $6^{\circ} \times 6^{\circ}$. Among GOSAT, OCO-2, and TanSat, the satellite observation validation characteristics near $5^{\circ} \times 5^{\circ}$ from the ground-based station are obviously different from other spatial matching grids, which may be due to the different observation characteristics of satellites near $5^{\circ} \times 5^{\circ}$. To study the influence of local $\mathrm{CO}_{2}$ sources on the characteristics of satellite observation validation, we classified the daily $\mathrm{XCO}_{2}$ observation sequence into concentrated, dispersive, increasing, and decreasing types, respectively, and then validated the satellite observations. The results showed that the concentrated and decreasing sub-datasets have better validation performance. Our results suggest that it is best to use concentrated and decreasing sub-datasets when using the Beijing Satellite Meteorological Ground Station $\mathrm{XCO}_{2}$ for satellite validation. The temporal matching setting should be $\pm 1 \mathrm{~h}$, and the spatial matching setting should consider the satellites observation characteristics of $5^{\circ} \times 5^{\circ}$ distance from the ground-based station.
\end{abstract}

Keywords: FTS; carbon dioxide; daily time series feature; colocation sensitivity; satellite validation

\section{Introduction}

In recent years, greenhouse gas (GHGs) emissions have reached unprecedented levels. Carbon dioxide $\left(\mathrm{CO}_{2}\right)$ has the highest concentration among the greenhouse gases in the atmosphere and constitutes about $63 \%$ of the radiative forcing by greenhouse gases $[1,2]$. Atmospheric $\mathrm{CO}_{2}$ has increased from 278 parts per million (ppm) in preindustrial times to 413.2 ppm in 2020 [3].

Remote sensing by satellites plays an important role in monitoring the global distribution of $\mathrm{CO}_{2}$. It is expected to improve the accuracy of the carbon budget and supplement the classic in situ measurement of $\mathrm{CO}_{2}$ [4]. With high spatial-temporal resolution, many researchers have demonstrated that the monitoring of atmospheric $\mathrm{CO}_{2}$ by satellites has the potential to reduce the uncertainties in estimating $\mathrm{CO}_{2}$ surface flux [5-7]. Furthermore, the inverse $\mathrm{CO}_{2}$ surface flux, $\mathrm{XCO}_{2}$ (the dry carbon dioxide column) product from satellites, needs an accuracy of $99.5 \%$ [8]. Early infrared band satellite detection payloads capable of 
detecting $\mathrm{CO}_{2}$ cannot detect near-ground source and sink information [9-11]. The reason is that the detection band is similar to the emission band of the surface of the earth, and it is difficult to distinguish the near-surface atmospheric signal. $\mathrm{CO}_{2}$-detecting satellites that also detect the reflection of the sun in the near-infrared band have been developed. Studies show that $\mathrm{CO}_{2}$ satellites carrying near-infrared detectors can obtain $\mathrm{XCO}_{2}$ with sufficient accuracy to estimate near-ground sources and sinks [12-14]. The first near-ground sensitive carbon dioxide satellite, the Greenhouse Gases Observing Satellite (GOSAT), was launched by Japan in January 2009. Later, the Orbiting Carbon Observatory-2 (OCO-2) was launched by the National Aeronautics and Space Administration (NASA) in July 2014 [15]. In December 2016, the Global $\mathrm{CO}_{2}$ observation and monitoring satellite (TanSat) was launched by China [16]. Soon after, the GaoFen-5 (GF-5) in China and the GOSAT-2 in Japan were launched in 2018, about a year before the Orbiting Carbon Observatory-3 (OCO-3) was brought to the International Space Station by the CRS-17 Cargo Dragon Replenishment Mission in May 2019 [17]. Although satellite observations have shown great potential in estimating $\mathrm{CO}_{2}$ sources and sinks, ground-based observations as auxiliary data are still needed for validation of satellite observations.

With the higher intensity of incident light observed by a ground-based Fourier Transform Spectrometer (FTS), higher quality spectra are available compared to those observed by satellites. Since a ground-based FTS detects direct sunlight, while satellites detect sunlight reflected by the earth, a ground-based FTS has a higher signal-to-noise ratio than a satellite does [18]. The Total Carbon Column Observing Network (TCCON) (Figure 1) is a global network for ground-based FTSs, which operates in the near-infrared spectral region to record direct solar spectra [19]. One of the aims of TCCON is to provide accurate measurements of $\mathrm{CO}_{2}$ for calibrating satellite-based retrieved $\mathrm{CO}_{2}$. The ground-based FTS data from TCCON were widely used in validating the $\mathrm{XCO}_{2}$ data products of satellites [19-32].

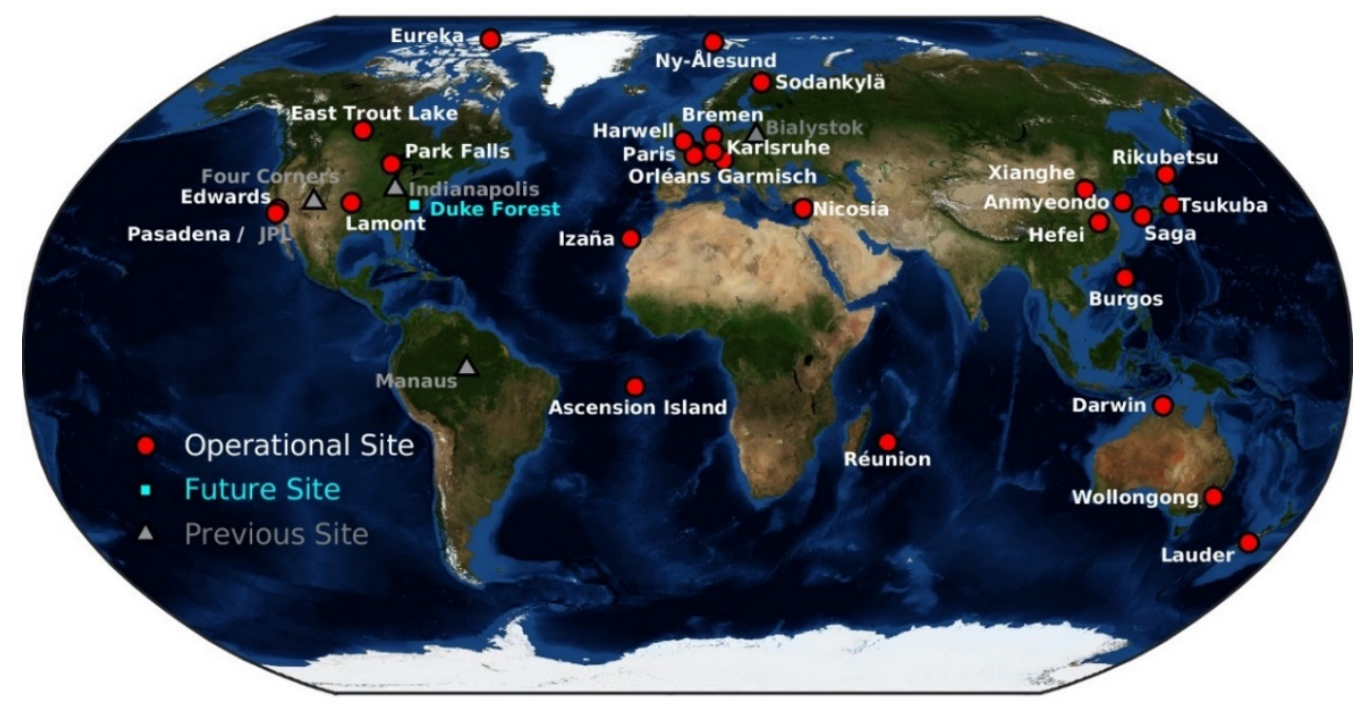

Figure 1. TCCON site map: red dots denote operational FTS sites, and the solid blue square denotes the future site (https: / tccon-wiki.caltech.edu/Main/TCCONSites (accessed on 10 November 2021)).

In December 2015, a ground-based FTS with high-resolution dedicated to recording the near-infrared direct solar spectra at Beijing in China was installed. A three-year-long ground-based FTS measurement campaign was undertaken in Beijing from 2 March 2016 to 4 December 2018. To study the impacts of the spatial-temporal matching strategy of ground-based validation in urban areas and the characteristics of the ground-based observation sequences on validation, we analyzed the sensitivity of the ground-based data validation for the GOSAT, OCO-2, and TanSat data to spatial-temporal matching. Based on the characteristics of the daily time series, the dataset is then classified into sub-datasets, and the sensitivity analysis of spatial-temporal matching with satellite data is performed. 


\section{Materials and Methods}

\subsection{Site FTS Measurements and Retrieval Method}

The FTS site is located at the Beijing Meteorological Satellite Ground Station $\left(40^{\circ} 3^{\prime} \mathrm{N}\right.$; $116^{\circ} 16.8^{\prime}$ E; 51 m.a.s.l.), in the center of Beijing (Figure 2), with an average elevation of $45 \mathrm{~m}$. The site is located in a densely populated area in Beijing, and many large Internetbased companies are located around it. The measurements at Beijing are made by a highresolution FTS (Bruker 125HR, Bruker Optics, Germany) and a solar tracker (A547N, Bruker Optics, Germany) (Figure 3). The FTS records the near-infrared spectra $\left(4000-10,000 \mathrm{~cm}^{-1}\right)$ with a resolution of $0.02 \mathrm{~cm}^{-1}$, covering the retrieval bands of $\mathrm{XCO}_{2}$. The ground-based FTS obtains direct solar absorption measurements under clear sky conditions and has been operational since December 2015.

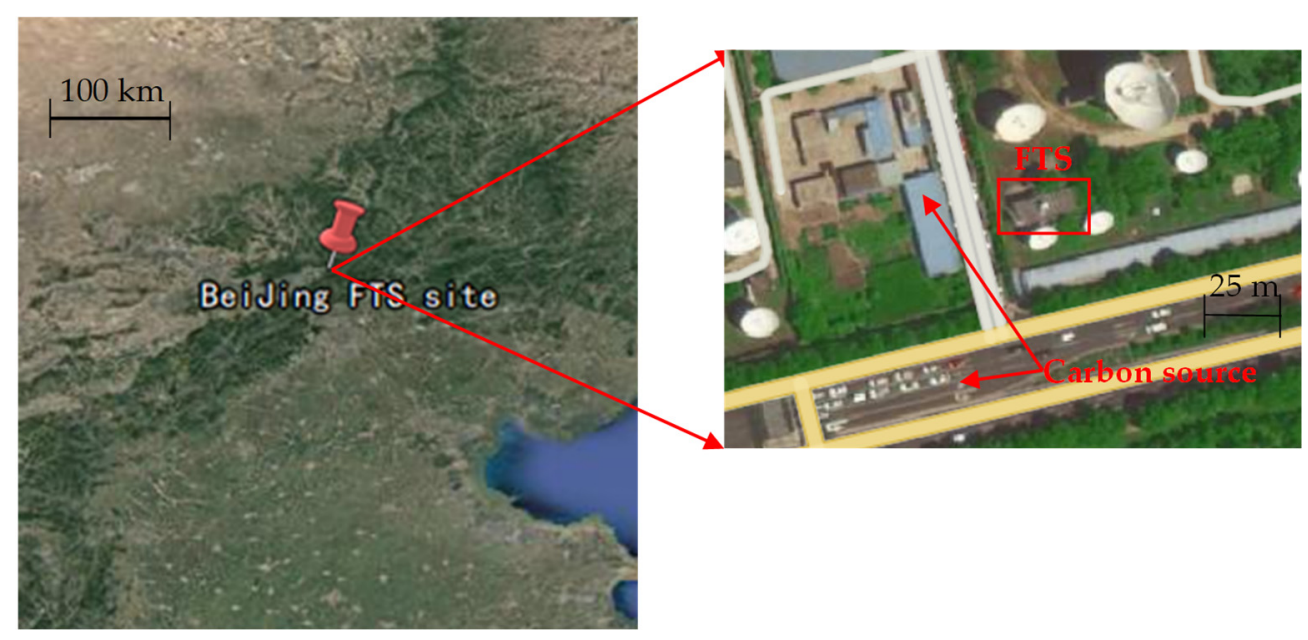

Figure 2. The location of the FTS site on Google Maps.
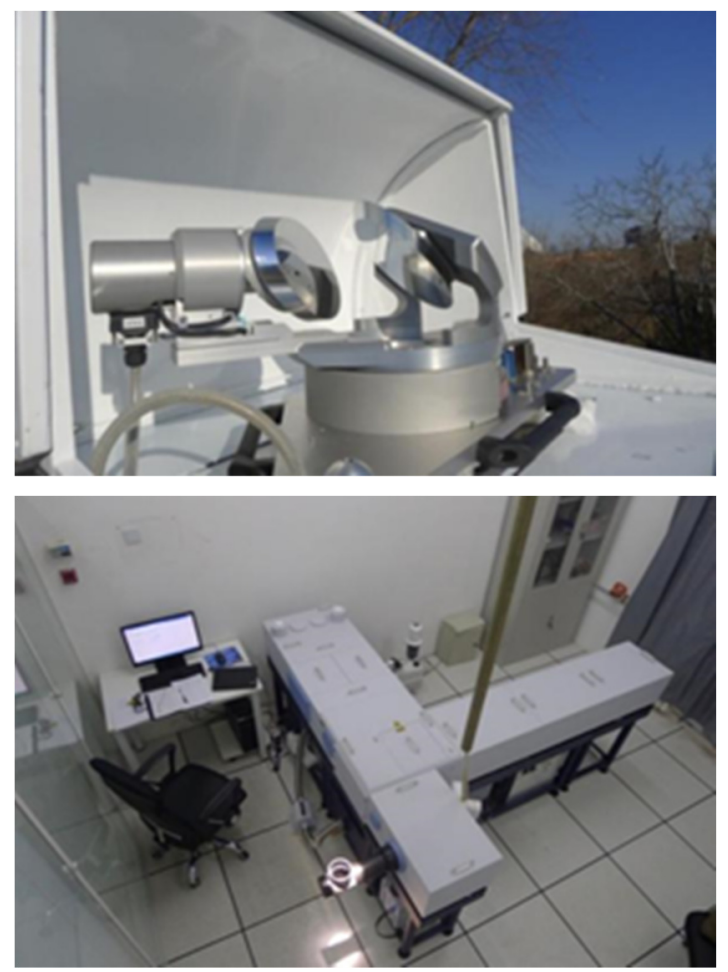

Figure 3. The site consists of the solar tracker on the surface and the FTS below. 
Near the FTS instrument, an automatic meteorological station in the meteorological observation network of the Chinese meteorological administration was used to monitor the surface temperature, pressure, relative humidity, and wind velocity. We operated the measurement routines during the validation campaign from 2 March 2016 to 4 December 2018, weather permitting. The data are generally not compromised by clouds and adverse weather conditions, as we only collected data on sunny days. The interferogram of the solar shortwave spectrum was recorded by the FTS every five minutes. We recorded 7118 spectra during these three years. Those spectra were prepared to retrieve $\mathrm{XCO}_{2}$ for the validation of $\mathrm{CO}_{2}$ monitoring satellites.

The standard retrieval software for TCCON, GGG, is utilized to retrieve gases from the spectra collected by FTS, while GFIT is the algorithm of GGG. The GFIT algorithm performs a least-square spectral fit over a prescribed window of a series of spectra to determine the slant column abundances of the fitted gases [33]. The algorithm was developed by Geoff Toon at the Jet Propulsion Laboratory (JPL) and has been adopted by TCCON to analyze the spectral data recorded by the ground-based FTS [34]. Total column $\mathrm{CO}_{2}$ is retrieved in two bands, $\left(6310.00-6380.00 \mathrm{~cm}^{-1}\right)$ and $\left(6180.00-6260.00 \mathrm{~cm}^{-1}\right)$, and the official report shows that the measurement uncertainty of the TCCON XCO 2 retrievals is smaller than $0.25 \%$. The a priori profiles of temperature, pressure, water vapor, and geopotential height are derived from the National Centers for Environmental Prediction/National Center for Atmospheric Research (NCEP/NCAR) reanalysis data.

The retrieved results of atmospheric composition are in units of parts per million (ppm) and can be strongly affected by the surface pressure and the topography. The $\mathrm{XCO}_{2}$ retrievals are less sensitive to variations in the surface pressure. This characteristic can provide direct comparisons to minimize the error of the measurements of trace gases in the atmosphere between different sites, during different seasons, and with in situ measurements. The $\mathrm{XCO}_{2}$ results observed from the ground are shown in Figure 4.

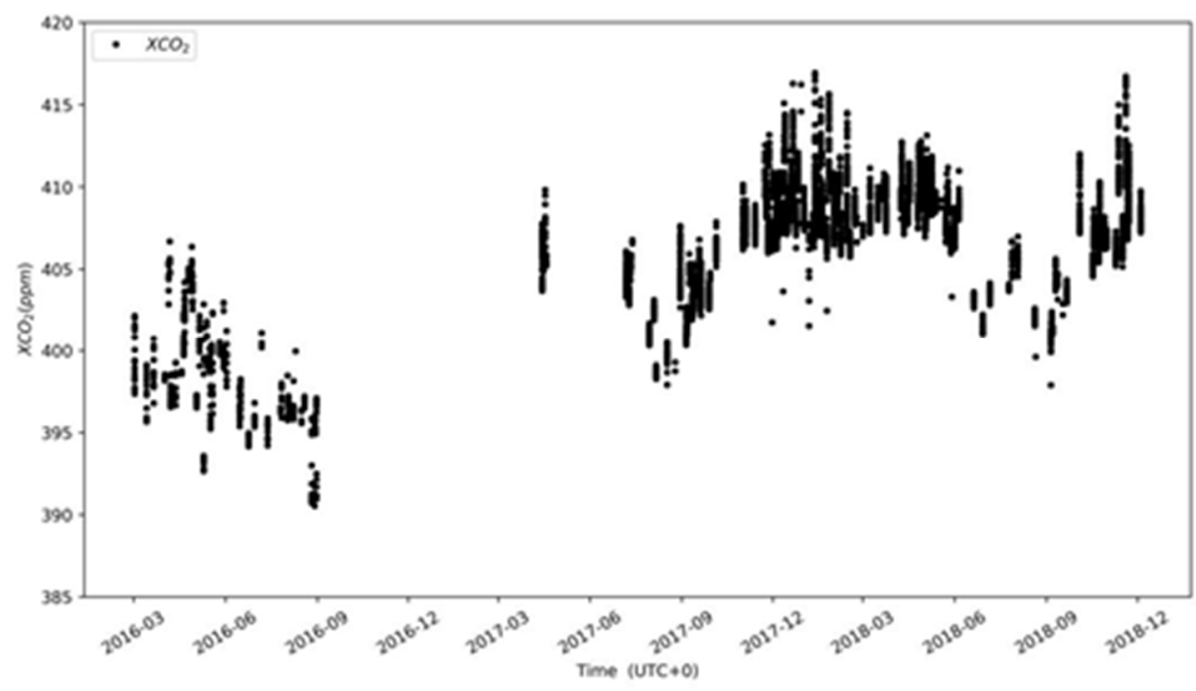

Figure 4. The FTS $\mathrm{XCO}_{2}$ data sequence.

\subsection{Satellite Data}

\subsubsection{GOSAT Data}

Jointly developed by JAXA, NIES, and MOE, GOSAT is a project designed to detect $\mathrm{CO}_{2}$ and methane in the atmosphere. GOSAT was launched into a sun-synchronous orbit with an inclination angle of $98^{\circ}$ and an altitude of $666 \mathrm{~km}$ on 23 January 2009 [35]. The time for GOSAT to complete one orbit is about $100 \mathrm{~min}$, the revisit period is three days, and the time to cross the local equator is 13:00 local time. GOSAT is equipped with two instruments, namely the Thermal and Near Infrared Sensor for Carbon Observations Fourier-Transform Spectrometer (TANSO-FTS) and the Thermal and the Near Infrared Sensor for Carbon Observation-Cloud and Aerosol Imager (TANSO-CAI). The TANSO-FTS 
is the main instrument used to detect $\mathrm{CO}_{2}$ and $\mathrm{CH}_{4}$ [20]. The FTS contains three narrow bands with central wavelengths of $0.76 \mu \mathrm{m}, 1.61 \mu \mathrm{m}$, and $2.06 \mu \mathrm{m}$ in the visible, nearinfrared, and a wide band in the thermal near-infrared of 5.56-14.3 $\mu \mathrm{m}$. The TANSO-CAI is a camera that observes the daytime state of the atmosphere and land surface and provides additional aerosol and cloud information for the FTS. The field of view of the TANSO-FTS is $15.8 \mathrm{mrad}$, the diameter of the nadir footprint is $10.5 \mathrm{~km}$, and the observation time of a single datapoint is $4 \mathrm{~s}$ [36].

GOSAT SWIR L2 Data has two major versions: v01.xx and v02.xx. Compared with the $\mathrm{XCO}_{2}$ of TCCON and GOSAT, the $\mathrm{XCO}_{2}$ retrieval results based on v01.xx showed negative biases of $-8.85 \mathrm{ppm}$ and standard deviations of $4.75 \mathrm{ppm}$, which are much higher than the $\mathrm{XCO}_{2}$ results from version 02.xx [23]. As a result of the updated solar irradiation database and aerosol scattering calculation, the errors of the v01.xx algorithm were corrected. The version 02.xx total data, after screening, are more than that of version 01.xx, and the $\mathrm{XCO}_{2}$ of version 02.xx were of high quality (biases of $-1.48 \mathrm{ppm}$ and standard deviation of 2.09 ppm compared with TCCON XCO ${ }_{2}$ ) [24]. We used version 02.085 SWIR $\mathrm{XCO}_{2} \mathrm{~L} 2$ data in this paper (Figure 5a).

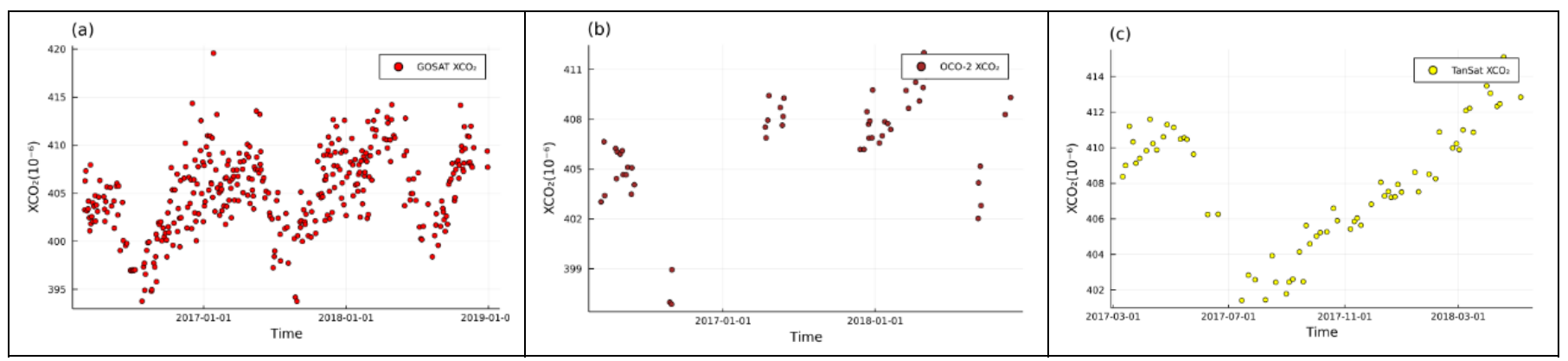

Figure 5. Time series of (a) GOSAT, (b) OCO-2, and (c) TanSat $\mathrm{XCO}_{2}$.

\subsubsection{OCO-2 Data}

The OCO-2 is a NASA project initiated for the accurate, precise, and high spatial distribution of $\mathrm{CO}_{2}$ detection. The $\mathrm{CO}_{2}$ retrievals of OCO-2 have sufficient precision and accuracy and can accurately describe the sources and sinks of $\mathrm{CO}_{2}$ as well as diagnose regional changes [37]. The OCO-2 satellite is a replica of the OCO that failed in 2009 [38]. OCO-2 was launched into the $705 \mathrm{~km}$ EOS A-train sun-synchronous orbit, located as the first satellite of the A-train. The orbital time is $98.8 \mathrm{~min}$, the intersection crossing time is 13:36 local time (LT), and the revisit period is 16 days. The OCO-2 satellite only carries a three-band grating imaging spectrometer. This spectrometer can detect near-infrared reflections and sun-scattered light from the surface of the earth, collecting the $0.765 \mu \mathrm{m}$ $\mathrm{O}_{2} \mathrm{~A}$ band as well as the $1.61 \mu \mathrm{m}$ and $2.06 \mu \mathrm{m}$ reflected sunlight spectra. The OCO-2 spectrometer collects eight continuous observations on the ground surface at a frequency of $3 \mathrm{~Hz}$. The footprint produced at the nadir is $2 \mathrm{~km}$ along the ground path, and the resolution of the vertical ground path is $1 \mathrm{~km} \mathrm{[15].}$

The ACOS algorithm is a $\mathrm{CO}_{2}$ retrieval process developed by the NASA ACOS team. The official L2 $\mathrm{XCO}_{2}$ products of OCO-2 are all based on the ACOS algorithm. The first version of the ACOS algorithm was released in 2012 [39]. Currently, the ACOS retrieval algorithm has nine versions. The latest three versions are ACOS B7, ACOS B8, and ACOS B9. Compared to ACOS B7, ACOS B8 updated the spectroscopy, land Bidirectional Reflectance Distribution Function (BRDF), Upper Tropospheric/Lower Stratospheric (UTLS) aerosol, GEOS5-FP-IT meteorology, and L1B improvement, plus numerous small changes. As a result, the $\mathrm{XCO}_{2}$ of version $\mathrm{B} 8$ data has $20 \%$ of the error variance of version 7 over land and $40 \%$ of the error variance of version 7 over the ocean [40]. ACOS version B9 revised the bias correction in ACOS version B8. It corrected for the observation point error and incorrect time sampling of the meteorological analyses in ACOS version B8, which resulted 
in a better estimate of surface pressure, helping to reduce $\mathrm{XCO}_{2}$ biases in regions of rough topography [41]. We used ACOS version B9 Lite $\mathrm{XCO}_{2} \mathrm{~L} 2$ data in this paper (Figure 5b).

\subsubsection{TanSat Data}

The TanSat satellite is the first Chinese satellite dedicated to the space-based remote sensing of atmospheric $\mathrm{CO}_{2}$. The TanSat satellite was successfully launched into a sunsynchronous orbit on 22 December 2016, with an orbital height of about $700 \mathrm{~km}$, an orbital inclination of $98.2^{\circ}$, and a local crossing of the equator at 13:30 LT [32]. TanSat carries two instruments, the Atmospheric Carbon Dioxide Grating Spectrometer (ACGS) and the Cloud and Aerosol Polarimetric Instrument (CAPI). The ACGS is a grating spectrometer for observing the backscattered light of the sun, used for $\mathrm{CO}_{2}$ inversion and oxygen inversion. It includes three sub-spectrometers to observe: the oxygen $\mathrm{A}$ band in the range of 758-778 nm, the weak absorption band of $\mathrm{CO}_{2}$ in the wavelength range of 1594-1624 nm, and the strong absorption band of $\mathrm{CO}_{2}$ in the range of 2042-2082 nm. CAPI is a multiband imager, including five bands ranging from ultraviolet to near-infrared (365-408 nm, $660-685 \mathrm{~nm}, 862-877 \mathrm{~nm}, 1360-1390 \mathrm{~nm}$, and 1628-1654 nm), used to obtain aerosol and cloud information. The $660-685 \mathrm{~nm}$ and $1628-1654 \mathrm{~nm}$ bands are used for polarization [42].

The TanSat global $\mathrm{XCO}_{2}$ product is retrieved by the IAPCAS (the Institute of Atmospheric Physics Carbon Dioxide Retrieval Algorithm for Satellite Remote Sensing) algorithm, which was developed by the Institute of Atmospheric Physics (IAP). It has a general accuracy of $2.11 \mathrm{ppm}$ and the absolute biases over TCCON stations such as Sodankyla and Karlsruhe are more than 2.9 ppm [43,44]. The ACOS $\mathrm{XCO}_{2}$ retrieval algorithm was used to process the TANSAT L1B data, noting that the average bias of ACOS algorithm is smaller than that of OCO-2, which is $0.85 \mathrm{ppm}$ [32]. The Department for Eco-Environmental Informatics (DEEI) of the State Key Laboratory of Resources and Environmental Information System of China has developed a TanSat Retrieval algorithm by combining the SCIATRAN radiation transfer model and OEM method. The $\mathrm{XCO}_{2}$ bias of the DEEI algorithm was $2.62 \mathrm{ppm}$ compared with the ground-based FTS measurement, with a standard deviation of $1.41 \mathrm{ppm}$ [45]. We use the DEEI XCO $\mathrm{XC}_{2}$ data in this paper (Figure 5c).

\subsection{Methods}

In areas far away from anthropogenic $\mathrm{CO}_{2}$ sources, the concentration of the $\mathrm{CO}_{2}$ column observed by ground-based observations is a concentrated quadratic function that first rises and then falls, as shown in Figure 6a [46]. Observations at the Beijing station are affected by near-surface anthropogenic sources, and, therefore, the daily change is no longer just showing a trend of rising first and then falling (Figure 6a). The sequences of continuous growth and continuous decline, as well as first decline and then rise, also appear in the observations at Beijing Station (Figure $6 \mathrm{~b}-\mathrm{d}$ ). Some daily sequences also show a trend of divergence (Figure $7 \mathrm{~b}$ ).

To study the impact of different types of ground-based data on satellite validation, we classify the daily $\mathrm{XCO}_{2}$ time series into four sub-datasets. The classification criteria are as follows. First-order fitting is performed on the daily sequence and the observation time; sequences with positive fitting coefficients are regarded as increasing types, and sequences with negative fitting coefficients are regarded as decreasing types. According to this method, the sequence that first increases and then decreases (Figure 6a) as well as the sequence that first decreases and then increases (Figure 6d) are recognized as increasing and decreasing types, respectively. If the number of points with an absolute difference between adjacent observations greater than $0.25 \mathrm{ppm}$ exceeds half of the total number of points, the sequence is identified as a dispersive sequence. Conversely, those that fail to meet the conditions are identified as a concentrated sequence. 


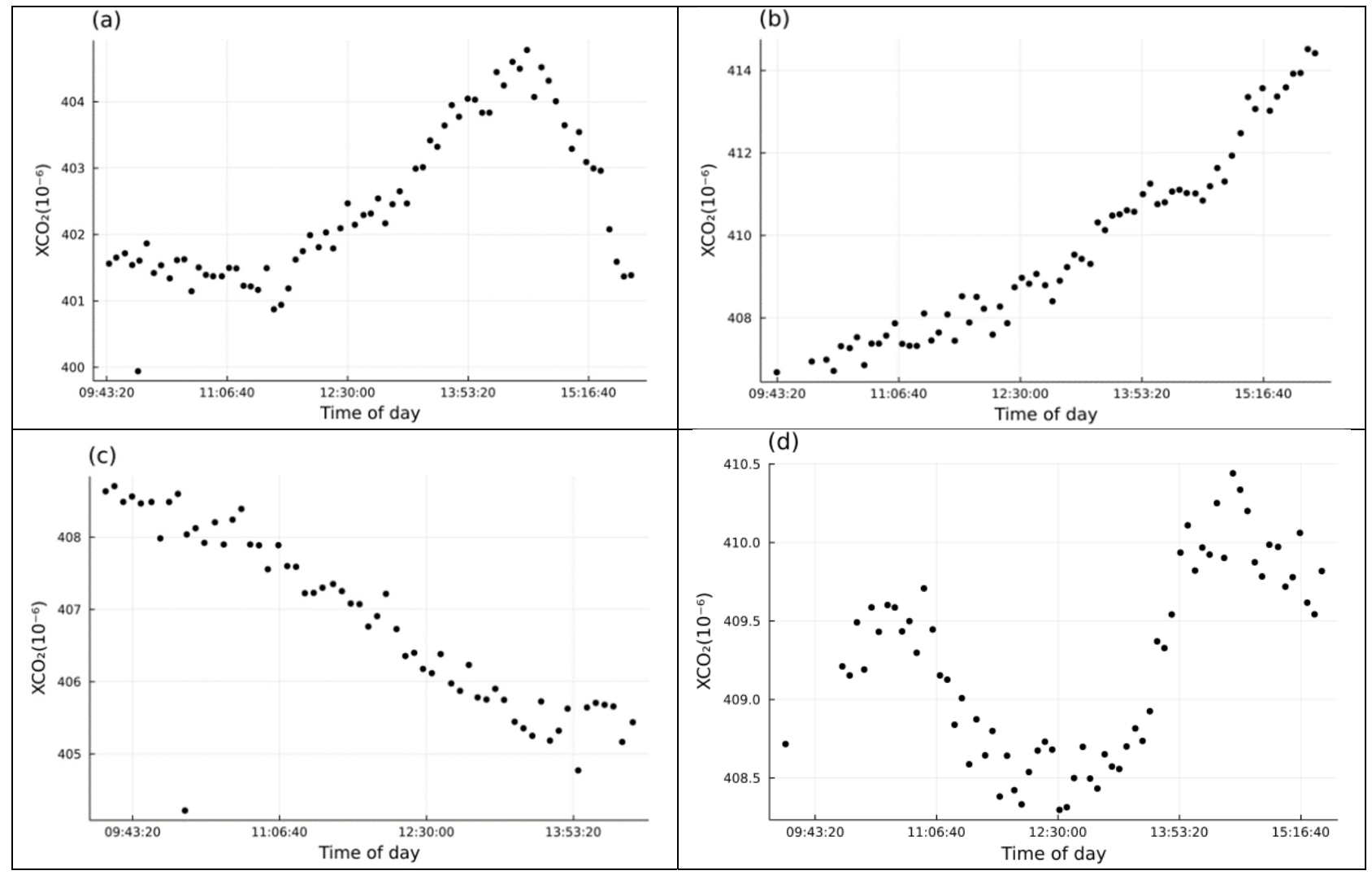

Figure 6. Four different types of time series, showing (a) first increase and then decrease, (b) consistent increase, (c) consistent decrease, and (d) first decrease and then increase.

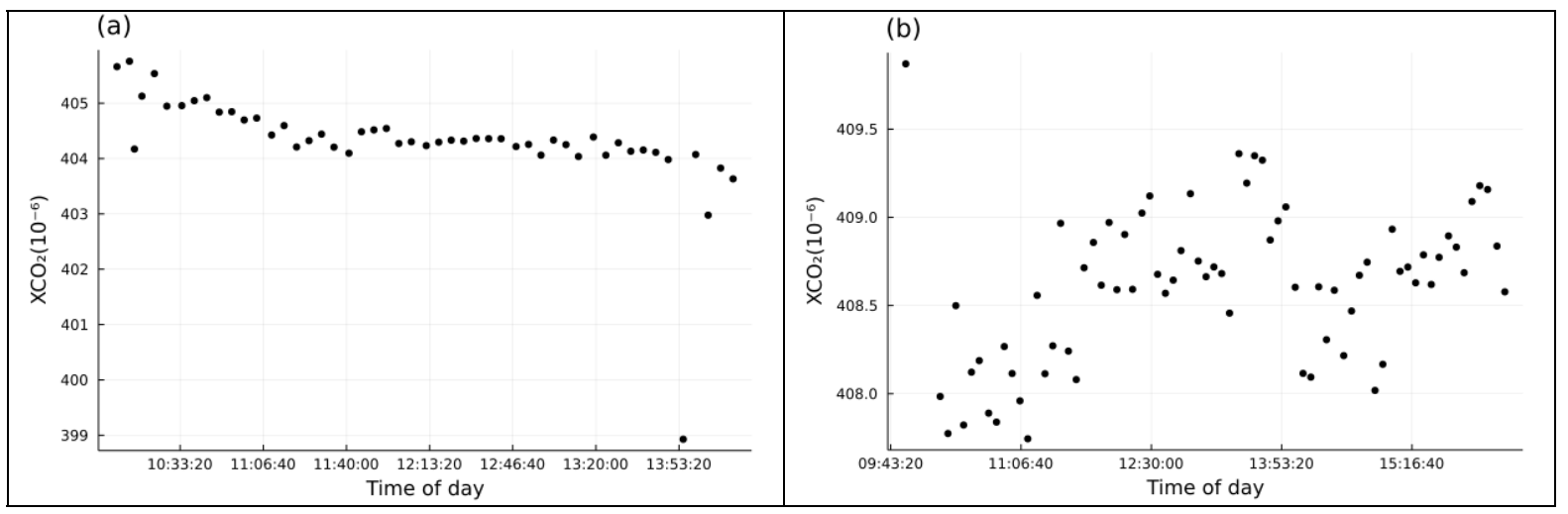

Figure 7. Examples of (a) concentrated time series and (b) dispersive time series.

The purpose of using ground-based data for validation is to limit the satellite and ground-based data to a certain space-time matching range. The satellites and groundbased data within the matching range are regarded as multiple measurements of the same amount, and the satellite data and ground-based data in the matching range are averaged as the representative data. The representative data of the ground is used as the proxy truth value. The bias, standard deviation, and Pearson correlation coefficient between the representative data of the satellite and the proxy truth value are evaluated. The bias represents the systematic error between the proxy truth value and the satellite representative data. During the calculation of the bias, the random error is eliminated by averaging the data. The standard deviation evaluates the degree of dispersion of the absolute difference between the representative data of the satellite and the proxy truth value and is used to represent the random error of the satellite observation. To describe the 
similarity between the satellite data and ground-based data, we use the Pearson correlation coefficient to evaluate the linear correlation between satellite data and ground-based data. The terms bias, $s d$, and $r$ represent the bias, standard deviation, and Pearson correlation coefficient, respectively; $X$ and $Y$ represent the ground-based $\mathrm{XCO}_{2}$ and satellite $\mathrm{XCO}_{2}$, respectively, and the formulas are as follows:

$$
\begin{gathered}
\text { bias }=\frac{\sum_{i=1}^{n}\left(X_{i}-Y_{i}\right)}{n} \\
s d=\sqrt{\frac{\sum_{i=1}^{n}\left(X_{i}-Y_{i}-\frac{\sum_{i=1}^{n}\left(X_{i}-Y_{i}\right)}{n}\right)^{2}}{n}} \\
r=\frac{\sum_{i=1}^{n}\left(X_{i}-\sum_{i=1}^{n} X_{i}\right) *\left(Y_{i}-\sum_{i=1}^{n} Y_{i}\right) / n}{\sqrt{\frac{\sum_{i=1}^{n}\left(X_{i}-\sum_{i=1}^{n} X_{i}\right)^{2} * \sum_{i=1}^{n}\left(Y-\sum_{i=1}^{n} Y_{i}\right)^{2}}{n^{2}}}}
\end{gathered}
$$

\section{Results}

To assess the performance of the observed Beijing ground-based data in the satellite validation, we use the comprehensive ground-based observation data to validate the GOSAT, OCO-2, and TanSat satellite data and proceed with the sensitivity analysis.

The standard of a good spatial-temporal matching strategy is that there is a large correlation coefficient and small bias compared to the real systematic error between satellite observation and ground-based observation as well as a small standard deviation between satellite data and ground-based data. The validation results of ground-based data and GOSAT data are shown in Figure 8. For the time matching strategy, the $\pm 1 \mathrm{~h}$ time matching strategy has the largest correlation coefficient and the smallest standard deviation, while the \pm 0.25 -h matching strategy has the smallest deviation and the smallest standard deviation. For the spatial matching setting, the $0.5^{\circ} \times 0.5^{\circ}$ spatial matching setting has the largest correlation coefficient, the smallest deviation, and the smallest standard deviation. When the spatial matching setting is either $4^{\circ} \times 4^{\circ}$ or $5^{\circ} \times 5^{\circ}$, the validation characteristics of ground-based data and satellite data are quite different from the smaller or larger spatial matching setting; that is to say, that a $4^{\circ} \times 4^{\circ}$ or $5^{\circ} \times 5^{\circ}$ has a small deviation and correlation coefficient with a large standard deviation.

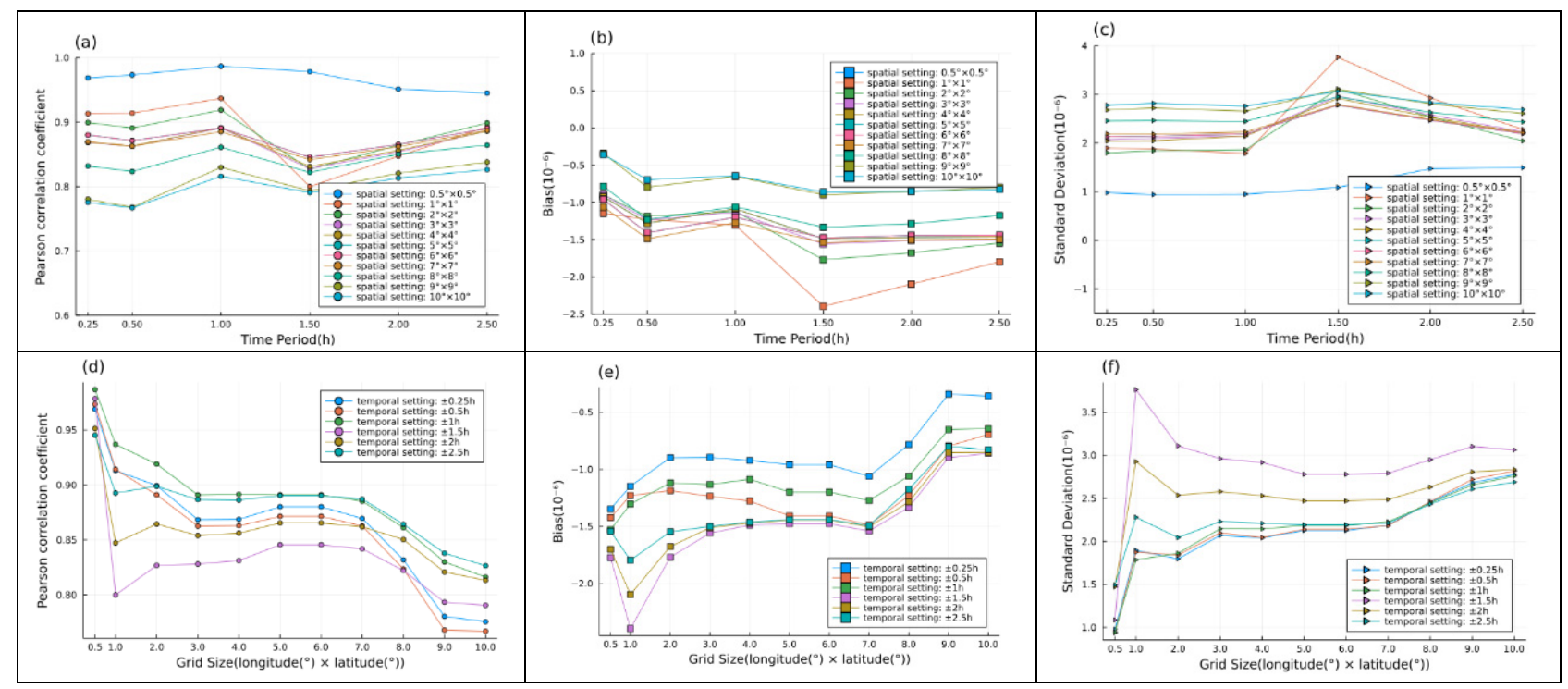

Figure 8. Sensitivity analysis results of validating ground-based data and GOSATdata. (a) Pearson correlation coefficient, (b) bias, and (c) standard deviation of time sensitivity verification, under different spatial matching settings. (d) Pearson correlation coefficient, (e) bias, and (f) standard deviation of the spatial sensitivity verification, under different time matching settings. 
Ground-based data and OCO-2 validation results show that, overall, $\pm 1 \mathrm{~h}$ is the best time matching strategy (Figure 9). For the spatial matching setting, the $4^{\circ} \times 4^{\circ}$ has the smallest deviation and standard deviation, but its correlation coefficient is too small. Spatial matching settings of $5^{\circ} \times 5^{\circ}$ and $6^{\circ} \times 6^{\circ}$ have the largest correlation coefficients and smaller standard deviations. Similar to GOSAT, the OCO- 2 and ground-based validation results show that under both $5^{\circ} \times 5^{\circ}$ and $6^{\circ} \times 6^{\circ}$ spatial matching settings, the validation characteristics are quite different from the smaller or larger spatial matching settings. The correlation coefficients for the $5^{\circ} \times 5^{\circ}$ and $6^{\circ} \times 6^{\circ}$ spatial matching settings validation results are much larger than the smaller or larger spatial matching strategies, and the biases are much larger than the smaller spatial matching settings and much smaller than the larger spatial matching settings. The standard deviations are much smaller than the larger space matching setting and much larger than the smaller space matching setting.

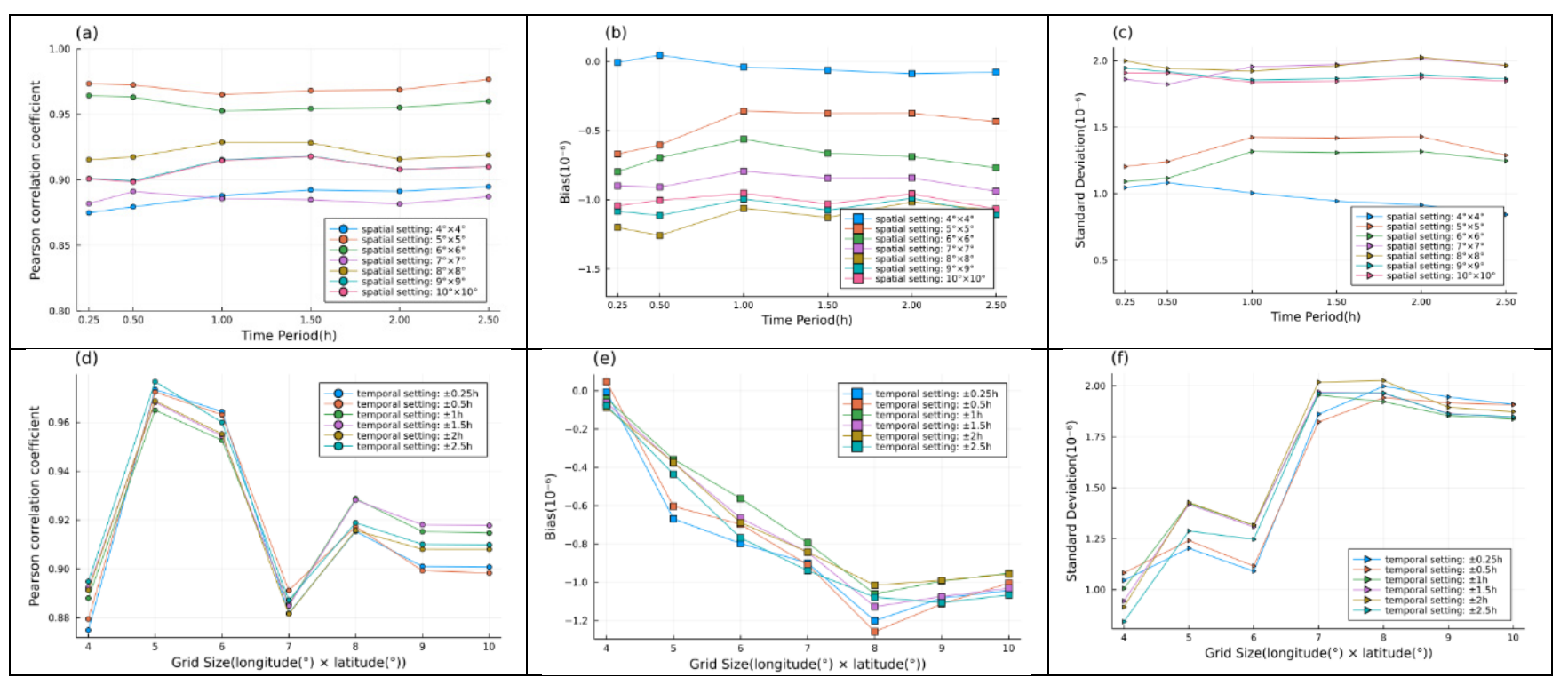

Figure 9. Sensitivity analysis results of validating ground-based data and OCO-2 data. (a) Pearson correlation coefficient, (b) bias, and (c) standard deviation of time sensitivity verification, under different spatial matching settings. (d) Pearson correlation coefficient, (e) bias, and (f) standard deviation of the spatial sensitivity verification, under different time matching settings.

There are a few matching points between the ground-based data and TanSat (Figure 10), and the validation results of different temporal and spatial matching are greatly affected by random errors. In the validation of the ground-based data and TanSat, the validation results of the $5^{\circ} \times 5^{\circ}$ and $6^{\circ} \times 6^{\circ}$ spatial matching settings are quite different from those of larger space matching settings. The spatial matching of $5^{\circ} \times 5^{\circ}$ or $6^{\circ} \times 6^{\circ}$ has a larger deviation and Pearson correlation coefficient, with a smaller standard deviation.

The datasets classified from the overall dataset are validated separately and subjected to sensitivity analysis. The sensitivity analysis results are compared with the overall validation results, and the relationship between different sub-datasets is analyzed. The four different types of result classifications are shown in Table 1.

Table 1. Time series classification results.

\begin{tabular}{ccccc}
\hline Classification & Increasing & Decreasing & Concentrated & Dispersive \\
\hline Number & 133 & 69 & 129 & 73 \\
\hline
\end{tabular}




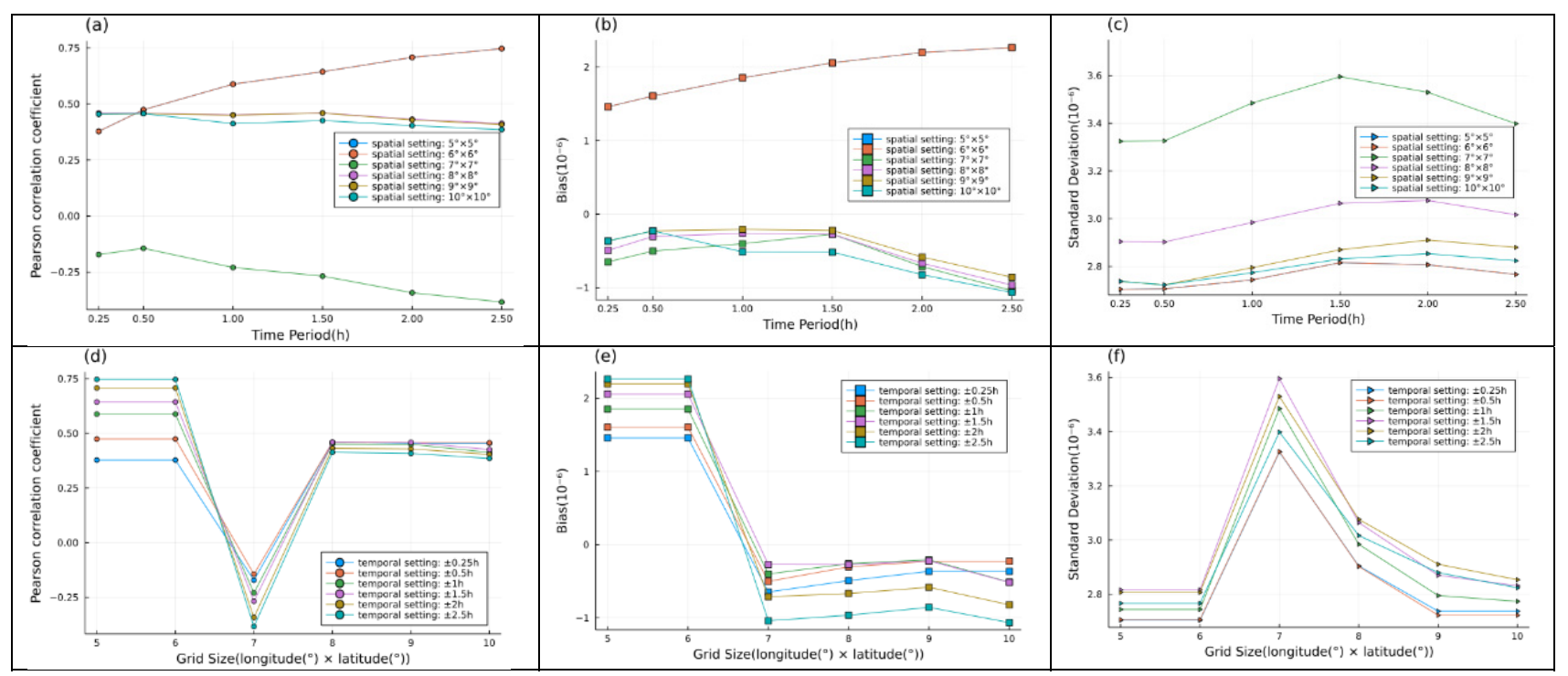

Figure 10. Sensitivity analysis results of validating ground-based data and TanSat data. (a) Pearson correlation coefficient, (b) bias, and (c) standard deviation of time sensitivity verification, under different spatial matching settings. (d) Pearson correlation coefficient, (e) bias, and (f) standard deviation of the spatial sensitivity verification, under different time matching settings.

To study the sensitivity of different types of sub-datasets to spatial matching settings, we choose $\pm 1 \mathrm{~h}$ as the time-matching setting and analyze the validation performance of the sub-datasets under different spatial matching settings on GOSAT and OCO-2 data.

Concentrated, dispersive, increasing, and decreasing sub-datasets have their own validation characteristics. As shown in Figures 11 and 12, validation results with GOSAT data and OCO-2 data show that the concentrated sub-dataset has larger bias and correlation coefficients as well as smaller standard deviations than the scattered sub-datasets. The decreasing sub-dataset has a larger bias and correlation coefficient as well as a smaller standard deviation than the increasing sub-dataset.

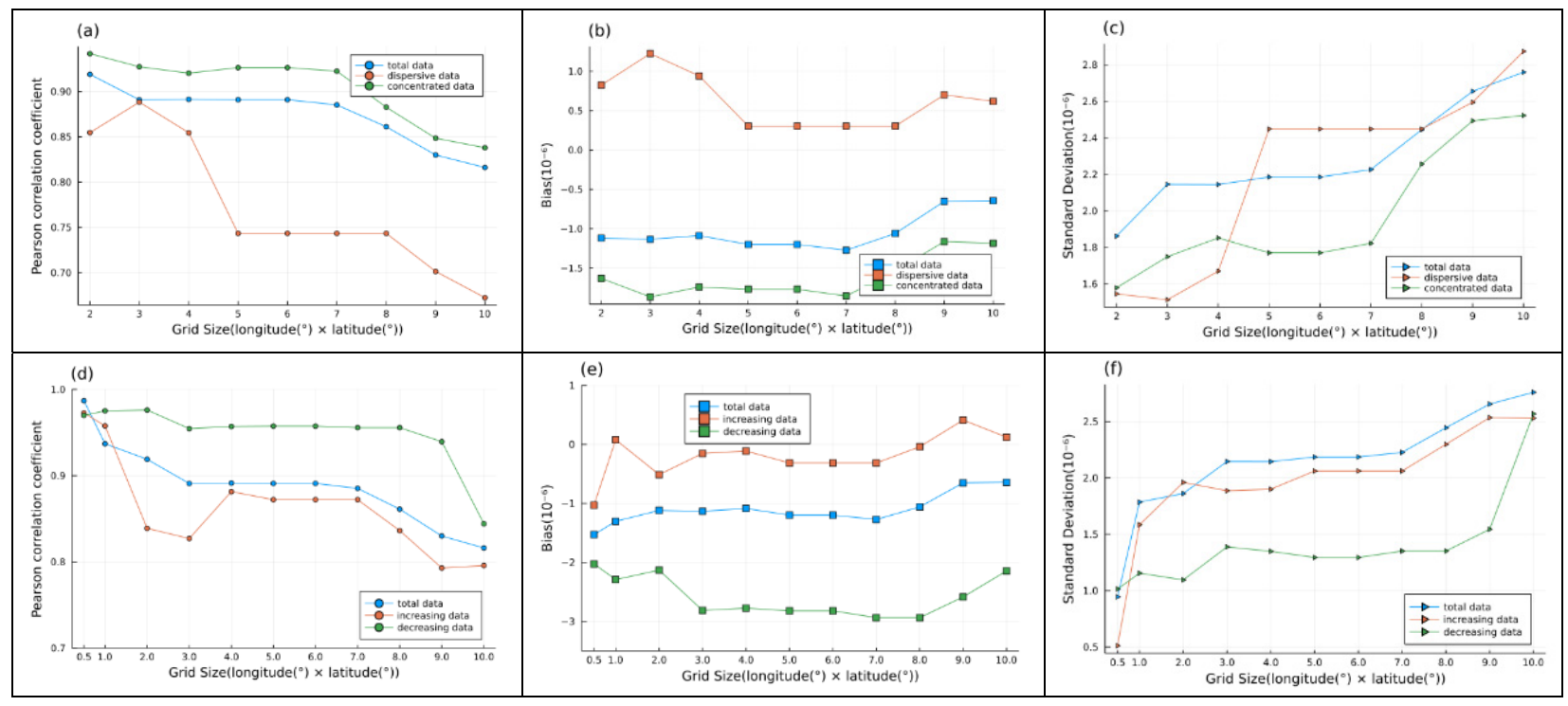

Figure 11. Sensitivity analysis results of validating classified ground-based data and GOSAT data as well as the comparison with total ground-based data. (a) Pearson correlation coefficient, (b) bias, and (c) standard deviation of spatial sensitivity validation and comparison of concentrated, dispersive, and total ground-based data, (d) Pearson correlation coefficient, (e) bias, and (f) standard deviation of the spatial sensitivity validation and comparison of increasing, decreasing, and total ground-based data. 


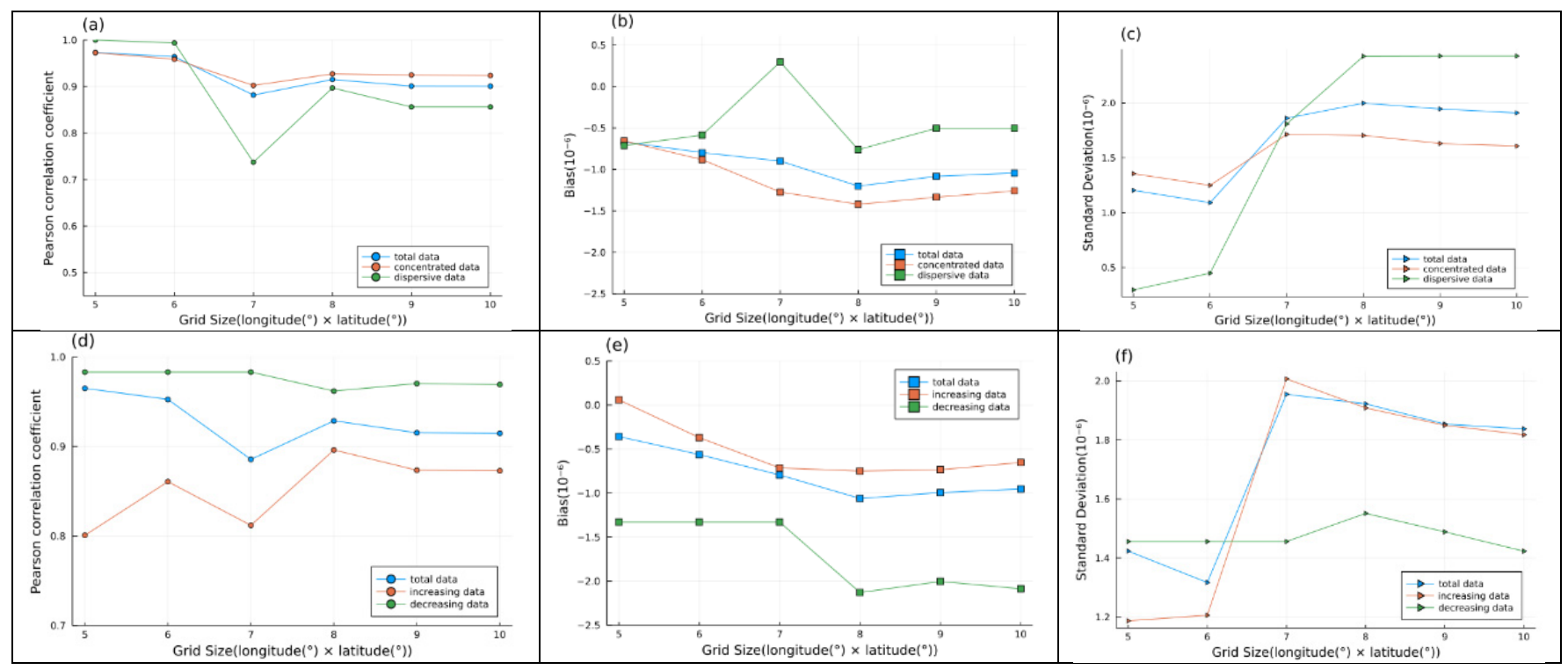

Figure 12. Sensitivity analysis results of validating classified ground-based data and OCO-2 data as well as the comparison with total ground-based data. (a) Pearson correlation coefficient, (b) bias, and (c) standard deviation of spatial sensitivity validation and comparison of concentrated, dispersive, and total ground-based data, (d) Pearson correlation coefficient, (e) bias, and (f) standard deviation of the spatial sensitivity validation and comparison of increasing, decreasing, and total ground-based data.

\section{Discussion}

The vertical column concentration measured by the ground is the integral of the $\mathrm{CO}_{2}$ concentration with respect to the depth of the entire atmosphere. It is insensitive to vertical transport and temporal changes and insensitive to zonal transport. Therefore, the vertical column concentration can reflect changes in surface flux [19]. In this study, we tested the validation sensitivity of $\mathrm{XCO}_{2}$ observed on the ground and obtained the optimal spatiotemporal matching settings for different satellite data. In order to study the influence of local sources on ground-based validation performance, we classified ground-based observation datasets into four categories for validation sensitivity tests and compared the validation performance differences between different categories.

Under time matching setting of $\pm 0.25 \mathrm{~h}$, there are fewer satellite and ground-based data within the matching range. The statistical results are greatly affected by random errors from a single measurement. Due to the weak sensitivity of ground-based observations of $\mathrm{XCO}_{2}$ data to time, increasing the time matching setting can expand the amount of matched satellite and ground-based observation data and reduce the influence of random errors on the validation results. When the time matching setting was increased to $\pm 1 \mathrm{~h}$, the best time matching setting is obtained.

The best spatial matching strategy between the ground-based data and GOSAT is $0.5^{\circ} \times 0.5^{\circ}$. Under this spatial matching setting, GOSAT and ground-based instruments observe $\mathrm{XCO}_{2}$ in the same area; therefore, the ground-based data had good validation performance. When the spatial matching setting increases, the validation performance deteriorates rapidly (Figure 8). The reason is that the ground base station is in a city, and the surface type, atmospheric state, $\mathrm{CO}_{2}$ concentration field, etc., change rapidly, so the measurement of the satellite-derived $\mathrm{XCO}_{2}$ also changes. The best spatial matching setting for OCO-2 and TanSat data verification is $5^{\circ} \times 5^{\circ}$ or $6^{\circ} \times 6^{\circ}$. The possible reason is that the observations and ground-based observations of OCO-2 and TanSat at a distance of $5^{\circ} \times 5^{\circ}$ from the ground site are in good agreement, as shown in the discussion below.

In the ground-based validation, the satellite observations of GOSAT, OCO-2, and TanSat showed anomalies near the $5^{\circ} \times 5^{\circ}$ spatial matching setting. For GOSAT data, under $5^{\circ} \times 5^{\circ}$ or $4^{\circ} \times 4^{\circ}$ spatial settings, the validation performance is worse than smaller or larger spatial matching settings. For OCO-2 and TanSat data, under a $5^{\circ} \times 5^{\circ}$ or $6^{\circ} \times 6^{\circ}$ 
space setting, the validation performance is better than a larger spatial matching setting. Since the satellite representative data is the average of satellite observations in the spatial matching grid, the validation performance anomaly of the satellite observations in the $5^{\circ} \times 5^{\circ}$ space matching setting is derived from the satellite observation anomalies near $5^{\circ} \times 5^{\circ}$. The possible reason of satellite observation anomalies is the observation by the satellite of the water area at a distance of $5^{\circ} \times 5^{\circ}$ from the ground site.

When using ground-based data to validate satellite data, small bias, standard deviations, and large correlation coefficients are the criteria for judging that satellite data and satellite observations have good consistency. Satellite observations and ground-based observations have a fixed system bias. When comparing satellite validation characteristics of sub-datasets from the same ground-based dataset, the sub-datasets whose deviations are close to the fixed system deviation of satellite observations and ground-based observations are more representative of ground-based observations, as opposed to the sub-data set whose deviation is close to zero. The validation results of four classified sub-datasets show that the concentrated and decreasing sub-datasets have higher validation performance, compared with the scattered and increasing sub-datasets, respectively. The possible reason is that the concentrated and decreasing sub-datasets are less affected by the $\mathrm{CO}_{2}$ source of the ground base station; therefore, the ground-based observations and the satellite observation data within the space-time matching range have a better consistency.

A study used $\mathrm{CO}_{2}$ observations at the TCCON Caltech site in Los Angeles to validate the $\mathrm{CO}_{2}$ observed by OCO-3. The results of this study showed that the root mean square error (RMSE) between satellite data and ground-based data was $0.23 \mathrm{ppm}$, and the Pearson correlation coefficient was 0.99 [47]. In this study, the spatial matching setting is $0.1^{\circ} \times 0.1^{\circ}$, which is smaller than the spatial matching setting tested in our research, partly because the Caltech site is very close to the water area, which will affect the validation performance of satellite observations. Unlike the classification methods we use in this study, the method of identifying local sources is to compare satellite observations in urban areas with observations far away from urban areas. In another study, $\mathrm{CO}_{2}$ observations were used as an indicator of anthropogenic sources [48]. In future research, we will combine the above two methods of local source identification to study the impact of urban anthropogenic sources on the performance of ground-based observation validation.

Based on our study, we recommend that: (1) the best time matching strategy for validation of Beijing ground-based $\mathrm{XCO}_{2}$ and satellite $\mathrm{CO}_{2}$ is $\pm 1 \mathrm{~h}$, the best space matching setting for GOSAT is $0.5^{\circ} \times 0.5^{\circ}$, and the best spatial matching setting for OCO-2 and TanSat is $5^{\circ} \times 5^{\circ}$ or $6^{\circ} \times 6^{\circ}$. (2) The data validation feature at a distance of $5^{\circ} \times 5^{\circ}$ from the Beijing Observation Station is significantly different from other spatial matching grids. The use of this spatial grid for ground-based validation needs to consider the observation characteristics of satellite observations in this spatial grid. (3) It is a better choice to use concentrated or decreasing sub-datasets for satellite validation in the Beijing FTS site.

Author Contributions: Conceptualization, X.Z. (Xingying Zhang), X.M., L.Z. and S.Y.; data curation, S.Y., X.M., L.Z., W.B., Z.D., X.Z. (Xin Zhang) and X.C.; software, X.M., W.B., L.Z. and S.Y.; supervision, X.Z. (Xingying Zhang), P.Z. and Z.Y.; visualization, S.Y., X.M. and L.Z.; writing-original draft preparation, S.Y. and X.M.; writing-review and editing, S.Y., L.Z. and X.Z. (Xingying Zhang). All authors have read and agreed to the published version of the manuscript.

Funding: This work is funded by the National Natural Science Foundation of China (No.: 41775028), National Key Research and Development Program Earth Observation and Navigation Key Project (No. 2017YFB0504001, No. 2016YFB0500705).

Institutional Review Board Statement: Not applicable.

Informed Consent Statement: Not applicable.

Data Availability Statement: GOSAT data can be downloaded from the GOSAT Data Archive Service (GDAS); OCO-2 data needs to be downloaded from the NASA earth data service. 
Acknowledgments: The authors acknowledge the satellite data from GOSAT, OCO-2, and TanSat. We thank TCCON for providing us with the distribution map of the TCCON site and the retrieval software GGG. We thank NCEP and NCAR for providing us with a priori information of atmospheric conditions.

Conflicts of Interest: The authors declare no conflict of interest.

\section{References}

1. Josep, G.; Canadell, J.G.; Monteiro, P.M.S.; Costa, M.H.; Cotrim da Cunha, L.; Cox, P.M.; Eliseev, A.V.; Henson, S.; Ishii, M.; Jaccard, S.; et al. Global Carbon and other Biogeochemical Cycles and Feedbacks. In Climate Change 2021: The Physical Science Basis. Contribution of Working Group I to the Sixth Assessment Report of the Intergovernmental Panel on Climate Change; Masson-Delmotte, V., Zhai, P., Pirani, A., Connors, S.L., Péan, C., Berger, S., Caud, N., Chen, Y., Goldfarb, L., Gomis, M.I., et al., Eds.; Cambridge University Press: Cambridge, UK, 2021; in press.

2. WMO. WMO Greenhouse Gas Bulletin (GHG Bulletin)-No.17: The State of Greenhouse Gases in the Atmosphere Based on Global Observations through 2020. 2021. Available online: https://public.wmo.int/en/media/press-release/greenhouse-gasbulletin-another-year-another-record (accessed on 10 November 2021).

3. Krings, T.; Neininger, B.; Gerilowski, K.; Krautwurst, S.; Buchwitz, M.; Burrows, J.P.; Lindemann, C.; Ruhtz, T.; Schüttemeyer, D.; Bovensmann, $\mathrm{H}$. Airborne remote sensing and in situ measurements of atmospheric $\mathrm{CO}_{2}$ to quantify point source emissions. Atmos. Meas. Tech. 2018, 11, 721-739. [CrossRef]

4. Chevallier, F. Impact of correlated observation errors on inverted $\mathrm{CO}_{2}$ surface fluxes from OCO measurements. Geophys. Res. Lett. 2007, 34. [CrossRef]

5. Rayner, P.J.; O'Brien, D.M. The utility of remotely sensed $\mathrm{CO}_{2}$ concentration data in surface source inversions. Geophys. Res. Lett. 2001, 28, 175-178. [CrossRef]

6. $\quad$ Feng, L.; Palmer, P.I.; Bösch, H.; Parker, R.J.; Webb, A.J.; Correia, C.S.C.; Deutscher, N.M.; Domingues, L.G.; Feist, D.G.; Gatti, L.V.; et al. Consistent regional fluxes of $\mathrm{CH}_{4}$ and $\mathrm{CO}_{2}$ inferred from GOSAT proxy $\mathrm{XCH}_{4}$ : $\mathrm{XCO}_{2}$ retrievals, 2010-2014. Atmos. Chem. Phys. 2017, 17, 4781-4797. [CrossRef]

7. Bovensmann, H.; Buchwitz, M.; Burrows, J.P.; Reuter, M.; Krings, T.; Gerilowski, K.; Schneising, O.; Heymann, J.; Tretner, A.; Erzinger, J. A remote sensing technique for global monitoring of power plant $\mathrm{CO}_{2}$ emissions from space and related applications. Atmos. Meas. Tech. 2010, 3, 781-811. [CrossRef]

8. Pagano, T.S.; Picard, R.H.; Chahine, M.T.; Schäfer, K.; Comeron, A.; Fetzer, E.J.; van Weele, M. The Atmospheric Infrared Sounder (AIRS) on the NASA Aqua Spacecraft: A general remote sensing tool for understanding atmospheric structure, dynamics, and composition. In Proceedings of the Remote Sensing of Clouds and the Atmosphere XV, Toulouse, France, 21-23 September 2010.

9. Beer, R. TES on the aura mission: Scientific objectives, measurements, and analysis overview. IEEE Trans. Geosci. Remote Sens. 2006, 44, 1102-1105. [CrossRef]

10. Goldberg, M.D.; Blumstein, D.; Bloom, H.J.; Tournier, B.; Cayla, F.R.; Huang, A.H.; Ardanuy, P.E.; Phulpin, T.; Fjortoft, R.; Buil, C.; et al. In-flight performance of the infrared atmospheric sounding interferometer (IASI) on METOP-A. In Proceedings of the Atmospheric and Environmental Remote Sensing Data Processing and Utilization III: Readiness for GEOSS, San Diego, CA, USA, 27-28, 30 August 2007.

11. Wang, J.S.; Kawa, S.R.; Collatz, G.J.; Sasakawa, M.; Gatti, L.V.; Machida, T.; Liu, Y.; Manyin, M.E. A Global Synthesis Inversion Analysis of Recent Variability in $\mathrm{CO}_{2}$ Fluxes Using GOSAT and In Situ Observations. Atmos. Chem. Phys. 2018, 18, 11097-11124. [CrossRef]

12. Basu, S.; Baker, D.F.; Chevallier, F.; Patra, P.K.; Liu, J.; Miller, J.B. The impact of transport model differences on $\mathrm{CO}_{2}$ surface flux estimates from OCO-2 retrievals of column average $\mathrm{CO}_{2}$. Atmos. Chem. Phys. 2018, 18, 7189-7215. [CrossRef]

13. Yang, D.; Liu, Y.; Feng, L.; Wang, J.; Yao, L.; Cai, Z.; Zhu, S.; Lu, N.; Lyu, D. The First Global Carbon Dioxide Flux Map Derived from TanSat Measurements. Adv. Atmos. Sci. 2021, 38, 1433-1443. [CrossRef]

14. Butler, J.J.; Xiong, X.; Gu, X.; Crisp, D. Measuring atmospheric carbon dioxide from space with the Orbiting Carbon Observatory-2 (OCO-2). In Proceedings of the Earth Observing Systems XX, San Diego, CA, USA, 9-13 August; 2015.

15. Ran, Y.; Li, X. TanSat: A new star in global carbon monitoring from China. Sci. Bull. 2019, 64, 284-285. [CrossRef]

16. Taylor, T.E.; Eldering, A.; Merrelli, A.; Kiel, M.; Somkuti, P.; Cheng, C.; Rosenberg, R.; Fisher, B.; Crisp, D.; Basilio, R.; et al. OCO-3 early mission operations and initial (vEarly) $\mathrm{XCO}_{2}$ and SIF retrievals. Remote Sens. Environ. 2020, 251, 112032. [CrossRef]

17. Li, Z.Q.; Xie, Y.S.; Gu, X.F.; Li, D.H.; Li, K.T.; Zhang, X.Y.; Wu, J.; Xiong, W. Atmospheric column $\mathrm{CO}_{2}$ measurement from a new automatic ground-based sun photometer in Beijing from 2010 to 2012. Atmos. Meas. Tech. Discuss. 2012, 5, 8313-8341. [CrossRef]

18. Wunch, D.; Toon, G.C.; Blavier, J.F.; Washenfelder, R.A.; Notholt, J.; Connor, B.J.; Griffith, D.W.; Sherlock, V.; Wennberg, P.O. The total carbon column observing network. Philos. Trans. A Math. Phys. Eng. Sci. 2011, 369, 2087-2112. [CrossRef]

19. Morino, I.; Uchino, O.; Inoue, M.; Yoshida, Y.; Yokota, T.; Wennberg, P.O.; Toon, G.C.; Wunch, D.; Roehl, C.M.; Notholt, J.; et al. Preliminary validation of column-averaged volume mixing ratios of carbon dioxide and methane retrieved from GOSAT short-wavelength infrared spectra. Atmos. Meas. Tech. Discuss. 2010, 3, 5613-5643. [CrossRef] 
20. Cogan, A.J.; Boesch, H.; Parker, R.J.; Feng, L.; Palmer, P.I.; Blavier, J.F.L.; Deutscher, N.M.; Macatangay, R.; Notholt, J.; Roehl, C.; et al. Atmospheric carbon dioxide retrieved from the Greenhouse gases Observing SATellite (GOSAT): Comparison with ground-based TCCON observations and GEOS-Chem model calculations. J. Geophys. Res. Atmos. 2012, 117, 21. [CrossRef]

21. Oshchepkov, S.; Bril, A.; Yokota, T.; Morino, I.; Yoshida, Y.; Matsunaga, T.; Belikov, D.; Wunch, D.; Wennberg, P.; Toon, G.; et al. Effects of atmospheric light scattering on spectroscopic observations of greenhouse gases from space: Validation of PPDF-based $\mathrm{CO}_{2}$ retrievals from GOSAT. J. Geophys. Res. Atmos. 2012, 117, 12. [CrossRef]

22. Oshchepkov, S.; Bril, A.; Yokota, T.; Wennberg, P.O.; Deutscher, N.M.; Wunch, D.; Toon, G.C.; Yoshida, Y.; O’Dell, C.W.; Crisp, D.; et al. Effects of atmospheric light scattering on spectroscopic observations of greenhouse gases from space. Part 2: Algorithm intercomparison in the GOSAT data processing for $\mathrm{CO}_{2}$ retrievals over TCCON sites. J. Geophys. Res. Atmos. 2013, 118, 1493-1512. [CrossRef]

23. Yoshida, Y.; Kikuchi, N.; Morino, I.; Uchino, O.; Oshchepkov, S.; Bril, A.; Saeki, T.; Schutgens, N.; Toon, G.C.; Wunch, D.; et al. Improvement of the retrieval algorithm for GOSAT SWIR $\mathrm{XCO}_{2}$ and $\mathrm{XCH}_{4}$ and their validation using TCCON data. Atmos. Meas. Tech. 2013, 6, 1533-1547. [CrossRef]

24. Nguyen, H.; Osterman, G.; Wunch, D.; O’Dell, C.; Mandrake, L.; Wennberg, P.; Fisher, B.; Castano, R. A method for colocating satellite $\mathrm{XCO}_{2}$ data to ground-based data and its application to ACOS-GOSAT and TCCON. Atmos. Meas. Tech. Discuss. 2014, 7, 2631-2644. [CrossRef]

25. Zhang, M.; Zhang, X.-Y.; Liu, R.-X.; Hu, L.-Q. A study of the validation of atmospheric $\mathrm{CO}_{2}$ from satellite hyper spectral remote sensing. Adv. Clim. Chang. Res. 2014, 5, 131-135. [CrossRef]

26. Zhou, M.; Zhang, X.; Wang, P.; Wang, S.; Guo, L.; Hu, L. XCO 2 satellite retrieval experiments in short-wave infrared spectrum and ground-based validation. Sci. China Earth Sci. 2015, 58, 1191-1197. [CrossRef]

27. Deng, A.; Yu, T.; Cheng, T.; Gu, X.; Zheng, F.; Guo, H. Intercomparison of Carbon Dioxide Products Retrieved from GOSAT Short-Wavelength Infrared Spectra for Three Years (2010-2012). Atmosphere 2016, 7, 109. [CrossRef]

28. Inoue, M.; Morino, I.; Uchino, O.; Nakatsuru, T.; Yoshida, Y.; Yokota, T.; Wunch, D.; Wennberg, P.O.; Roehl, C.M.; Griffith, D.W.T.; et al. Bias corrections of GOSAT SWIR $\mathrm{XCO}_{2}$ and $\mathrm{XCH}_{4}$ with TCCON data and their evaluation using aircraft measurement data. Atmos. Meas. Tech. 2016, 9, 3491-3512. [CrossRef]

29. Kulawik, S.; Wunch, D.; O’Dell, C.; Frankenberg, C.; Reuter, M.; Oda, T.; Chevallier, F.; Sherlock, V.; Buchwitz, M.; Osterman, G.; et al. Consistent evaluation of ACOS-GOSAT, BESD-SCIAMACHY, CarbonTracker, and MACC through comparisons to TCCON. Atmos. Meas. Tech. 2016, 9, 683-709. [CrossRef]

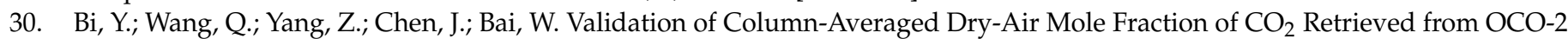
Using Ground-Based FTS Measurements. J. Meteorol. Res. 2018, 32, 433-443. [CrossRef]

31. Wang, S.; van der A, R.J.; Stammes, P.; Wang, W.; Zhang, P.; Lu, N.; Zhang, X.; Bi, Y.; Wang, P.; Fang, L. Carbon Dioxide Retrieval from TanSat Observations and Validation with TCCON Measurements. Remote Sens. 2020, 12, 2204. [CrossRef]

32. Toon, G.; Sen, B.; Blavier, J.F.; Sasano, Y.; Yokota, T.; Kanzawa, H.; Ogawa, T.; Suzuki, M.; Shibasaki, K. Comparison of ILAS and MkIV profiles of atmospheric trace gases measured above Alaska in May 1997. J. Geophys. Res. Atmos. 2002, 107, ILS 8-1-ILS 8-6. [CrossRef]

33. Connor, B.J.; Sherlock, V.; Toon, G.; Wunch, D.; Wennberg, P.O. GFIT2: An experimental algorithm for vertical profile retrieval from near-IR spectra. Atmos. Meas. Tech. 2016, 9, 3513-3525. [CrossRef]

34. Yokota, T.; Yoshida, Y.; Eguchi, N.; Ota, Y.; Tanaka, H.; Watanabe, H.; Maksyutov, S. Global Concentrations of $\mathrm{CO}_{2}$ and $\mathrm{CH}_{4}$ Retrieved from GOSAT: First Preliminary Results. Sci. Online Lett. Atmos. Sola 2009, 5, 160-163. [CrossRef]

35. Kuze, A.; Suto, H.; Nakajima, M.; Hamazaki, T. Thermal and near infrared sensor for carbon observation Fourier-transform spectrometer on the Greenhouse Gases Observing Satellite for greenhouse gases monitoring. Appl. Opt. 2009, 48, 6716-6733. [CrossRef]

36. Rastogi, B.; Miller, J.B.; Trudeau, M.; Andrews, A.E.; Hu, L.; Mountain, M.; Nehrkorn, T.; Baier, B.; McKain, K.; Mund, J.; et al. Evaluating consistency between total column $\mathrm{CO}_{2}$ retrievals from OCO-2 and the in situ network over North America: Implications for carbon flux estimation. Atmos. Chem. Phys. 2021, 21, 14385-14401. [CrossRef]

37. Meynart, R.; Pollock, R.; Neeck, S.P.; Haring, R.E.; Holden, J.R.; Shimoda, H.; Johnson, D.L.; Kapitanoff, A.; Mohlman, D.; Phillips, C.; et al. The Orbiting Carbon Observatory instrument: Performance of the OCO instrument and plans for the OCO-2 instrument. In Proceedings of the SPIE-The International Society for Optical Engineering, Toulouse, France, 20-23 September 2010; Volume 7826. [CrossRef]

38. O'Dell, C.W.; Connor, B.; Bösch, H.; O’ Brien, D.; Frankenberg, C.; Castano, R.; Christi, M.; Eldering, D.; Fisher, B.; Gunson, M.; et al. The $\mathrm{ACOS} \mathrm{CO}_{2}$ retrieval algorithm-Part 1: Description and validation against synthetic observations. Atmos. Meas. Tech. 2012, 5 , 99-121. [CrossRef]

39. O'Dell, C.W.; Eldering, A.; Wennberg, P.O.; Crisp, D.; Gunson, M.R.; Fisher, B.; Frankenberg, C.; Kiel, M.; Lindqvist, H.; Mandrake, L.; et al. Improved retrievals of carbon dioxide from Orbiting Carbon Observatory-2 with the version 8 ACOS algorithm. Atmos. Meas. Tech. 2018, 11, 6539-6576. [CrossRef]

40. Kiel, M.; O’Dell, C.W.; Fisher, B.; Eldering, A.; Nassar, R.; MacDonald, C.G.; Wennberg, P.O. How bias correction goes wrong: Measurement of $\mathrm{XCO}_{2}$ affected by erroneous surface pressure estimates. Atmos. Meas. Tech. 2019, 12, 2241-2259. [CrossRef] 
41. Wang, X.; Guo, Z.; Huang, Y.; Fan, H.; Li, W. A cloud detection scheme for the Chinese Carbon Dioxide Observation Satellite (TANSAT). Adv. Atmos. Sci. 2016, 34, 16-25. [CrossRef]

42. Yang, D.; Liu, Y.; Boesch, H.; Yao, L.; Di Noia, A.; Cai, Z.; Lu, N.; Lyu, D.; Wang, M.; Wang, J.; et al. A New TanSat XCO 2 Global Product towards Climate Studies. Adv. Atmos. Sci. 2020, 38, 8-11. [CrossRef]

43. Liu, Y.; Yang, D.; Cai, Z. A retrieval algorithm for TanSat $\mathrm{XCO}_{2}$ observation: Retrieval experiments using GOSAT data. Chin. Sci. Bull. 2013, 58, 1520-1523. [CrossRef]

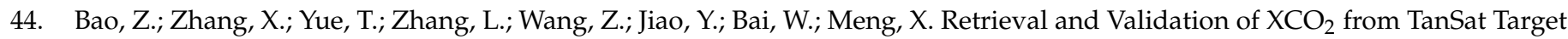
Mode Observations in Beijing. Remote Sens. 2020, 12, 3063. [CrossRef]

45. Velazco, V.A.; Deutscher, N.M.; Morino, I.; Uchino, O.; Bukosa, B.; Ajiro, M.; Kamei, A.; Jones, N.B.; Paton-Walsh, C.; Griffith, D.W.T. Satellite and ground-based measurements of $\mathrm{XCO}_{2}$ in a remote semiarid region of Australia. Earth Syst. Sci. Data 2019, 11, 935-946. [CrossRef]

46. Wunch, D.; Wennberg, P.O.; Osterman, G.; Fisher, B.; Naylor, B.; Roehl, C.M.; O’Dell, C.; Mandrake, L.; Viatte, C.; Kiel, M.; et al. Comparisons of the Orbiting Carbon Observatory-2 (OCO-2) $\mathrm{XCO}_{2}$ measurements with TCCON. Atmos. Meas. Tech. 2017, 10, 2209-2238. [CrossRef]

47. Kiel, M.; Eldering, A.; Roten, D.D.; Lin, J.C.; Feng, S.; Lei, R.; Lauvaux, T.; Oda, T.; Roehl, C.M.; Blavier, J.-F.; et al. Urban-focused satellite $\mathrm{CO}_{2}$ observations from the Orbiting Carbon Observatory-3: A first look at the Los Angeles megacity. Remote Sens. Environ. 2021, 258, 112314. [CrossRef]

48. Newman, S.; Jeong, S.; Fischer, M.L.; Xu, X.; Haman, C.L.; Lefer, B.; Alvarez, S.; Rappenglueck, B.; Kort, E.A.; Andrews, A.E.; et al. Diurnal tracking of anthropogenic $\mathrm{CO}_{2}$ emissions in the Los Angeles basin megacity during spring 2010. Atmos. Chem. Phys. 2013, 13, 4359-4372. [CrossRef] 